\title{
Erratum: Pregnancy Complicated by Gorham- Stout Disease and Refractory Chylothorax
}

\author{
${ }^{1}$ Department of Medicine, Stanford University, Palo Alto, California \\ ${ }^{2}$ Department of Surgery, University of California, San Francisco, \\ California \\ ${ }^{3}$ Department of Pediatrics, Stanford University, Palo Alto, California \\ ${ }^{4}$ Departments of Obstetrics and Gynecology, Stanford University, \\ Palo Alto, California \\ ${ }^{5}$ Division of Cardiovascular Medicine, Stanford Center for Lymphatic \\ and Venous Disorders, Stanford University School of Medicine, \\ Stanford, California
}

Jessica Hellyer, MD ${ }^{1}$ Hunter Oliver-Allen, MD ${ }^{2}$ Majid Shafiq, $\mathrm{MD}^{1}$ Alisha Tolani, BA ${ }^{1}$ Maurice Druzin, $\mathrm{MD}^{3,4}$ Michael Jeng, $\mathrm{MD}^{3} \quad$ Stanley Rockson, $\mathrm{MD}^{5}$ Robert Lowsky, MD ${ }^{1}$

Address for correspondence Jessica Hellyer, MD, Department of Medicine, Stanford University, 300 Pasteur Drive, Lane 154, Palo Alto, CA 94305 (e-mail: jhellyer@stanford.edu).

Am J Perinatol Rep 2016;6:e384.

\section{ERRATUM}

It has been brought to our attention that the degree of Alisha Tolani appeared incorrectly in the above article published online in American Journal of Perinatology Reports (volume 6, issue 4, pp. e355-e358; DOI: 10.1055/s-0036-1593443). The author degree is now correctly listed as BA in the above author byline. 